\title{
Virulence factors of bacteraemic Escherichia coli with particular reference to production of cytotoxic necrotising factor (CNF) by P-fimbriate strains
}

\author{
J. BLANCO, M.P. ALONSOt, E. A. GONZALEZ, M. BLANCO and J. I. GARABAL
}

Departamento de Microbiologia y Parasitologia, Facultad de Veterinaria, Universidad de Santiago, 27002 Lugo. and tLaboratorio de Microbiologica, Hospital de Corta, 27880 Burela, Lugo, Spain

\begin{abstract}
Summary. Thirty-seven strains of Escherichia coli isolated from bacteraemia and $\mathbf{4 0}$ faecal strains isolated from healthy individuals were $O$ serogrouped and investigated for the production of colicins, haemolysin (Hly), cytotoxic necrotising factor (CNF), lethal activity for mice, the expression of $\mathrm{P}$ fimbriae, mannose-resistant (MRHA) and mannose-sensitive (MSHA) haemagglutination, and relative cell surface hydrophobicity. Virulence factors significantly associated with bacteraemic strains were: serogroups $\mathrm{O} 2, \mathrm{O} 4, \mathrm{O} 6, \mathrm{O} 7, \mathrm{O} 8$ and $\mathrm{O} 75(54 \%$ versus $10 \%, \mathrm{p}<0.001)$, production of Hly $(32 \%$ versus $8 \%, \mathrm{p}<0.02)$ and CNF $(38 \%$ versus $10 \%, \mathrm{p}<0.01)$, expression of $\mathrm{P}$ fimbriae $(27 \%$ versus $5 \%, \mathrm{p}<0.02)$, MRHA types III, IVa and IVb $(51 \%$ versus $8 \%$, $\mathrm{p}<0.001)$, and possession of a moderate cell surface hydrophobic charge $(35 \%$ versus $13 \%, \mathrm{p}<0.05)$. Virulence factors were strongly associated with strains expressing defined MRHA types. Thus, all strains belonging to MRHA types III and IVa were toxigenic, whereas only $11 \%$ of strains belonging to MRHA types IVb, V or VI were toxigenic $(p<0.001)$. Virulence factors were concentrated in strains belonging to $O$ serogroups usually found in $E$. coli that cause extra-intestinal infections, especially in strains of $\mathrm{O} 4$ and $\mathrm{O6}$ groups. The most interesting result of this study was that all 12 P-fimbriate strains expressed the MRHA type IVa and 11 of them synthesised CNF.
\end{abstract}

\section{Introduction}

Escherichia coli is one of the most common microorganisms found in blood cultures. Bacteria reach the bloodstream from many different sites of infection, especially from the urinary tract (Kreger et al., 1980; Ørskov and Ørskov, 1985). Adherence of bacteria to the host epithelium is an important virulence factor; in $E$. coli this is mediated by fimbriae (or pili), which usually express haemagglutinating activity (Gaastra and de Graaf, 1982; Ørskov and Ørskov, 1985). Two major groups of fimbriae have been found in extra-intestinal $E$. coli: common type 1 fimbriae which are responsible for mannose-sensitive haemagglutination (MSHA), and $\mathrm{P}, \mathrm{S}, \mathrm{M}$, and $\mathrm{X}$ fimbriae that cause mannoseresistant haemagglutination (MRHA) (Väisänen $e t$ al., 1981; Domingue et al., 1985; Korhonen et al., 1985; Ørskov and Ørskov, 1985; Hacker et al., 1986; Brauner et al., 1987; Johnson et al., 1988). Many $E$. coli strains possess type 1 fimbriae, and generally no specific association has been demonstrated between the expression of these fimbriae

Received 7 April 1989; revised version accepted 8 Sept. 1989. and virulence. In contrast, mannose-resistant fimbriae are clearly associated with virulence (Ørskov and Ørskov, 1985). The most important mannoseresistant haemagglutinating fimbriae expressed by extra-intestinal $E$. coli are the $\mathrm{P}$ fimbriae, frequently detected in pyelonephritogenic $E$. coli (Väisänen $e t$ al., 1981; Domingue et al., 1985). Besides bacterial adherence, several virulence factors may contribute to the pathogenicity of bacteraemic $E$. coli. These include certain somatic (Vosti et al., 1964; Ørskov and Ørskov, 1975) and capsular antigens (Evans $e t$ al., 1981; Cross et al., 1984; Korhonen et al., 1985); resistance to the bactericidal activity of serum (Cross et al., 1984) and to phagocytosis (Weinstein and Young, 1978; Cross et al., 1984); expression of the siderophore aerobactin (Montgomerie et al., 1984; Johnson et al., 1988); and production of colicin V (Minshew et al., 1978) and haemolysin (Hly) (Minshew et al., 1978; Czirok, 1985). Furthermore, four toxins (LT, STa, VT and CNF) have been described in human $E$. coli strains. Enterotoxigenic $E$. coli synthesise heat-labile (LT) or heatstable (STa) enterotoxin, or both. Verotoxin (VT) is produced by enterohaemorrhagic $E$. coli of serotype 0157:H7 and some classical enteropatho- 
genic $E$. coli strains (Levine, 1987). Production of a cytotoxic necrotising factor (CNF) was found to be closely associated with $E$. coli strains causing urinary tract infections (Alonso et al., 1987; Caprioli et al., 1987).

We have developed (Blanco et al., 1985; Blanco et al., 1988a) a simple, rapid and economical MRHA typing system for $E$. coli, a modification of that originally described by Duguid et al. (1979) and Evans et al. $(1980,1981)$; it appears to be valid for the presumptive identification of pathogenic strains. MRHA strains were classified into six MRHA types (I-VI): (i) types I and II are expressed only by enterotoxigenic $E$. coli producing colonisation factors CFA/I and CFA/II respectively; (ii) types III and IVa are usually expressed by CNFand Hly-producing strains belonging to serotypes commonly identified in $E$. coli that cause extraintestinal infections; and (iii) types IVb, V and VI are not associated with pathogenic strains.

In this study the incidence of various virulenceassociated factors in $37 \mathrm{E}$. coli strains isolated from blood and in 40 control strains isolated from faeces of healthy people was investigated.

\section{Materials and methods}

\section{Bacterial strains}

Thirty-seven $E$. coli strains were isolated from the blood of patients with bacteraemia in the Hospital Juan Canalejo in La Coruña (North-western Spain) from 1986 to 1988 . The mean age of the patients was 64 years (range 3 days to 84 years). Underlying medical illnesses were present, singly or in combination, in $62 \%$ of the patients. The most common underlying diseases were neoplasia $(24 \%)$ and diabetes $(16 \%)$. Bacteraemias were associated with urinary tract infections $(43 \%)$, abdominal infections $(19 \%)$, and respiratory tract infections $(11 \%)$, but $27 \%$ of the patients had bacteraemia without an identifiable source. Sixty-eight percent were community acquired and $32 \%$ hospital acquired bacteraemias. Forty strains isolated from stools of healthy individuals of widely varying age groups were used as controls. A single $E$. coli colony was chosen from each individual. Isolation and identification of $E$. coli were by standard bacteriological methods. Strains were stored at room temperature in Nutrient Broth with agar (Difco) $0.75 \%(w / v)$.

\section{Toxin production}

Erlenmeyer flasks of $250-\mathrm{ml}$ volume containing $20 \mathrm{ml}$ Tryptone Soya Broth (Oxoid) ( $\mathrm{pH} \mathrm{7.5),} \mathrm{were} \mathrm{inoculated}$ with a loopful of the test strain taken from solid medium and incubated in an orbital shaker $(200 \mathrm{rpm})$ at $37^{\circ} \mathrm{C}$ for $20 \mathrm{~h}$. To obtain sonic extracts for testing, whole cultures $\left(7 \times 10^{9} \mathrm{cfu} / \mathrm{ml}\right)$ were disintegrated in an ice bath with an
MSE ultrasonic disintegrator at an amplitude of $10 \mu \mathrm{m}$ peak for $5 \mathrm{~min}$. After sonication, cultures were centrifuged $\left(6000 \mathrm{~g}\right.$ for $15 \mathrm{~min}$ at $4^{\circ} \mathrm{C}$ ) and the supernatant fractions were filter sterilised. Sonic extracts were assayed the same day or stored at $-20^{\circ} \mathrm{C}$ for a maximum period of 7 days (Alonso et al., 1987; Blanco et al., 1988a).

\section{Detection of CNF, LT and VT on Vero cells}

Sonic extracts from $E$. coli strains were assayed on Vero cell monolayers in plastic plates (Alonso et al., 1987; Blanco et al., 1988a); $0.05 \mathrm{ml}$ of sonic extract was added to each well with Vero monolayers and $0.5 \mathrm{ml}$ of fresh Eagle's Minimum Essential Medium (Flow Laboratories) without fetal calf serum and supplemented with polymyxin B sulphate (Gibco) 50 units $/ \mathrm{ml}$ and $0.05 \mathrm{~mm}$ methyl-isobutyl-xanthine (Sigma) as phosphodiesterase inhibitor. Cultures were incubated at $37^{\circ} \mathrm{C}$ in an atmosphere of air $+\mathrm{CO}_{2} \quad 5 \%$ and the morphological changes in cells were observed after incubation for 24 and $48 \mathrm{~h}$. Specific morphological changes caused by CNF, LT and VT on Vero cells may be observed in fig. 1 (González and Blanco, 1985; Blanco et al., 1988b).

\section{Animal assays}

Necrotising activity was detected by the skin test performed in New Zealand albino rabbits weighing 2.0 $2.5 \mathrm{~kg}$. Hair was shaved from the back of the animals and $0.1 \mathrm{ml}$ of each sonic extract was injected intradermally into three rabbits following a random pattern. Forty-eight hours after inoculation, the presence of necrotic reactions was assessed by inspecting for ulceration and induration at the injection sites. Sonic extracts were considered to give positive reactions when they produced necrosis in at least two of the three animals. Mouse lethality was assayed by intraperitoneal injection of sonic extracts $(0.5 \mathrm{ml}$ per mouse) into five BALB/c mice $(25-30 \mathrm{~g})$. The number of mice that died during a week was scored. We considered the extract to have obvious lethal activity when at least three of the five mice died.

\section{Haemolysin production}

Haemolysis was assayed on Blood Agar Base medium (Merck, FRG) containing washed sheep erythrocytes 5\% $\mathrm{v} / \mathrm{v}$. Strains that produced a clear zone of lysis $(\beta-$ haemolysis) after incubation for $24 \mathrm{~h}$ at $37^{\circ} \mathrm{C}$ were considered to be haemolytic.

\section{Colicin production}

Tryptone Soya Medium (Oxoid) with agar $1.2 \%$ was inoculated with $E$. coli strains. After incubation for $24 \mathrm{~h}$ at $37^{\circ} \mathrm{C}$, the organisms were killed by treatment with chloroform vapour (Merck) for $30 \mathrm{~min}$ and then opened to air for $1 \mathrm{~h}$. Next, the medium was overlaid with soft agar (agar 0.4\% and $\mathrm{NaCl} 0.5 \%$ in Nutrient Broth, Difco) 
containing $E$. coli $\mathrm{K} 12-711$ or $E$. coli K12-711-Colicin $\mathrm{V}^{+}, 10^{6} \mathrm{cfu} / \mathrm{ml}$. After incubation for $24 \mathrm{~h}$ at $37^{\circ} \mathrm{C}$, inhibition of the indicator strains by the test strain was scored. Strains that inhibited indicator strain K12-711 but not strain K12-711-Colicin $\mathrm{V}^{+}$were considered to be colicin V ( Col V) positive. Strains that inhibited both indicator strains were considered to produce non-V colicins.

\section{Haemagglutination test, $P$ fimbriae and cell surface hydrophobicity}

Bacteria were inoculated into Mueller Hinton Broth (Difco) and incubated statically at $37^{\circ} \mathrm{C}$ for 5 days until a pellicle was formed on the surface. From this pellicle, bacteria were recovered, inoculated on to CFA (Evans et al., 1980) and Minca-Is (Guinée et al., 1977) solid media and incubated at $37^{\circ} \mathrm{C}$ for $18 \mathrm{~h}$. Haemagglutination was determined by the rocked-tile method (Blanco et al., $1985,1988 a$ ) with human group A, calf, guinea-pig, adult chicken, sheep and pig erythrocytes and dense suspensions $\left(10^{12} \mathrm{cfu} / \mathrm{ml}\right.$ in PBS, $\mathrm{pH} \mathrm{7.4)}$ ) of bacteria grown on CFA and Minca-Is media. One drop of bacterial suspension was mixed with one drop of erythrocytes $(3 \%$ in PBS) and one drop of PBS (with or without D-mannose $3 \%$ in a depression on a tile. The tile was rocked for 5 min at ambient temperature followed by $5 \mathrm{~min}$ at $4^{\circ} \mathrm{C}$, and results were recorded after further incubation at ambient temperature and at $4^{\circ} \mathrm{C}$. Haemagglutination was considered resistant to mannose (MRHA) when it occurred in the presence and absence of mannose, and sensitive to mannose (MSHA) when it was inhibited by the presence of mannose. Strains were grouped according to their MRHA patterns in six MRHA types (I-VI): (i) type I characterised by $\mathrm{MRHA}^{+}$with human, calf and adult chicken erythrocytes and $\mathrm{MRHA}^{-}$with the remaining three erythrocyte species; (ii) type II, MRHA ${ }^{+}$ with calf and adult chicken erythrocytes and MRHA ${ }^{-}$ with the remaining four erythrocyte species; (iii) type III, $\mathrm{MRHA}^{+}$with human erythrocytes only after incubation at $4^{\circ} \mathrm{C}$ and with sheep and pig erythrocytes, and MRHA variable $(+$ or -$)$ with the remaining three erythrocyte species; (iv) type IVa, $\mathrm{MRHA}^{+}$with human erythrocytes at ambient temperatures and with sheep and pig erythrocytes, and MRHA variable with the remaining three erythrocyte species; (v) type IVb, $\mathrm{MRHA}^{+}$with human and pig erythrocytes. MRHA ${ }^{-}$with sheep erythrocytes and MRHA variable with the remaining three erythrocyte species; (vi) type $\mathrm{V}, \mathrm{MRHA}^{+}$with human erythrocytes and $\mathrm{MRHA}^{-}$with the remaining five erythrocyte species; and (vii) type VI, MRHA ${ }^{-}$with human erythrocytes and MRHA variable with the remaining five erythrocyte species.

Detection of $\mathbf{P}$ fimbriae was performed by a particle agglutination test (PF test, Orion Diagnostica, Espoo, Finland) which was specific for the $P$ receptor. The bacterial suspensions prepared for haemagglutination tests were employed for the detection of $\mathrm{P}$ fimbriae. Briefly, one drop of bacterial suspension was mixed with one drop of test solution containing latex particles coated with the $P$ receptor $\alpha-D-G a l-(1-4)-\beta-D-G a l$ on a plastic slide. Latex particles devoid of $P$ receptor served as a control. If $\mathbf{P}$ fimbriae were expressed by the organism, macroscopic agglutination was apparent, usually within $1 \mathrm{~min}$.

Relative cell surface hydrophobicity was measured by the improved salt aggregation test (ISAT) with suspensions $\left(5 \times 10^{9} \mathrm{cfu} / \mathrm{ml}\right.$ in $0.02 \mathrm{M}$ phosphate buffer, $\left.\mathrm{pH} 6.8\right)$ of bacteria grown on CFA and Minca-Is media (González et al., 1988). The final molar ammonium sulphate (Merck) concentrations used were $2 \cdot 0,1.4,1 \cdot 0,0.4,0.1,0.06$ and 0.02 . Strains were considered hydrophobic when they aggregated in $\leqslant 1.4 \mathrm{M}$ ammonium sulphate concentrations.

\section{Serotyping}

O serotyping of $E$. coli strains was performed in microtitration plates by the method of Guinée et al. (1972). The eight $\mathrm{O}$ antisera used $(\mathrm{O} 1, \mathrm{O} 2, \mathrm{O} 4, \mathrm{O6}, \mathrm{O}$, O8, 018 and 075 ) were selected on the basis of their frequent occurrence in $E$. coli isolates from blood (Vosti et al., 1964; Ørskov and Ørskov, 1975).

\section{Statistical methods}

Results were compared by the $\chi^{2}$ test with Yates' correction for continuity.

\section{Results}

Incidence of the virulence-associated factors in E. coli isolated from blood and faeces: relation to mouse lethality

Serogroups 02, O4, O6, O7, O8 and O75, the production of Hly and CNF, the expression of $P$ fimbriae, MRHA types III, IVa and IVb, and cell surface hydrophobicity were all more frequently detected in bacteraemic $E$. coli than in strains isolated from the faeces of healthy people (table I). In contrast, colicin production, mouse lethality, and the expression of MSHA and MRHA types V and VI were found in similar proportions in bacteraemic and control strains. When we examined the distribution of these characteristics in lethal and non-lethal strains, independent of their origin (blood or faeces), all characteristics except colicin production and the expression of MSHA and MRHA types IVb, V and VI, were closely associated with lethal strains (table II).

\section{Haemagglutinating properties}

All $E$. coli strains, grown on CFA and Minca-Is media, were tested for haemagglutination in the presence and absence of D-mannose. The results 
Table I. Distribution of virulence characters in bacteraemic $E$. coli strains and in isolates from the faeces of healthy people

\begin{tabular}{|c|c|c|c|}
\hline \multirow[b]{2}{*}{ Character } & \multicolumn{2}{|c|}{$\begin{array}{c}\text { Number }(\%) \text { of strains isolated } \\
\text { from }\end{array}$} & \multirow{2}{*}{$\begin{array}{c}\chi^{2} \\
\text { p value }\end{array}$} \\
\hline & blood $(n=37)$ & faeces $(n=40)$ & \\
\hline $\mathrm{O} 2, \mathrm{O} 4, \mathrm{O} 6, \mathrm{O} 7, \mathrm{O} 8$ and $\mathrm{O} 75$ groups & $20(54)$ & $4(10)$ & $<0.001$ \\
\hline Production of colicin V & $5(14)$ & $4(10)$ & $<0.90$ \\
\hline Production of other colicins & $11(30)$ & $16(40)$ & $<0 \cdot 50$ \\
\hline Production of Hly & $12(32)$ & $3(8)$ & $<0.02$ \\
\hline Production of CNF & $14(38)$ & $4(10)$ & $<0.01$ \\
\hline Mouse lethality & $9(24)$ & $7(18)$ & $<0.70$ \\
\hline Expression of $\mathbf{P}$ fimbriae & $10(27)$ & $2(5)$ & $<0.02$ \\
\hline MRHA types III, IVa and IVb & $19(51)$ & $3(8)$ & $<0.001$ \\
\hline MRHA types V and VI & $3(8)$ & $9(23)$ & $<0.20$ \\
\hline Expression of MSHA & $20(54)$ & $21(53)$ & $<0.95$ \\
\hline Moderate cell surface hydrophobicity & $13(35)$ & $5(13)$ & $<0.05$ \\
\hline
\end{tabular}

Table II. Presence of virulence characters in lethal and non-lethal E. coli strains

\begin{tabular}{lccc}
\hline \multicolumn{1}{c}{ Character } & \multicolumn{2}{c}{ Number (\%) of strains } & \\
\cline { 2 - 3 } & lethal $(\mathrm{n}=16)$ & non-lethal $(\mathrm{n}=61)$ & $\begin{array}{c}\chi^{2} \\
\text { p value }\end{array}$ \\
\hline O4, O6, O18 and O75 groups & $9(56)$ & $2(3)$ & $<0.001$ \\
Production of colicin V & $0(0)$ & $9(15)$ & $<0 \cdot 30$ \\
Production of other colicins & $5(31)$ & $22(36)$ & $<0.95$ \\
Production of Hly & $10(63)$ & $5(8)$ & $<0.001$ \\
Production of CNF & $11(69)$ & $7(11)$ & $<0.001$ \\
Expression of P fimbriae & $7(44)$ & $5(8)$ & $<0.01$ \\
MRHA types III and IVa & $11(69)$ & $5(8)$ & $<0.001$ \\
MRHA types IVb, V and VI & $1(6)$ & $17(28)$ & $<0.20$ \\
Expression of MSHA & $9(56)$ & $32(52)$ & $<0.99$ \\
Moderate cell surface hydrophobicity & $9(56)$ & $9(15)$ & $<0.01$ \\
& & & \\
\hline
\end{tabular}

were as follows : (i) all $41 \mathrm{MSHA}^{+}$strains expressed mannose-sensitive haemagglutination when grown on both media; (ii) 34 strains were $\mathrm{MRHA}^{+}$, including 29 that expressed the property when grown on both media, three only when grown on Minca-Is medium and two only when grown on CFA agar; (iii) 25 of the $29 \mathrm{MRHA}^{+}$strains expressed identical MRHA types when grown on CFA and Minca-Is media. E. coli strains were grouped according to their haemagglutinating phenotypes as shown in table III. Haemagglutinating strains were also grouped according to their MRHA patterns into six types (I-VI) (table IV) (Blanco et al., 1988a).

\section{Cell surface hydrophobicity}

Of the 77 strains, $18(23 \%)$ were moderately hydrophobic, aggregating in $\leqslant 1.4 \mathrm{M}$ ammonium sulphate concentrations. Four strains aggregated in $0.4 \mathrm{M}$ ammonium sulphate, and the other 14 strains in $1.0 \mathrm{M}$ or $1.4 \mathrm{M}$ solutions. Seven strains were hydrophobic when grown on CFA and Minca-Is media, five only when grown on CFA agar and six only when grown on Minca-Is medium. Hydrophobicity was found to be associated with haemagglutination; all 18 hydrophobic strains were haemagglutinating, whereas only 36 of the 59 nonhydrophobic strains were $(\mathrm{p}<0 \cdot 01)$. Furthermore, hydrophobic strains were more frequently detected among $\mathrm{MRHA}^{+} \mathrm{MSHA}^{+}$strains $(43 \%)$ than in $E$. coli expressing either MRHA (31\%) or MSHA $(25 \%)$ alone (table III). Hydrophobic strains were more common in $\mathrm{MRHA}^{+}$strains belonging to types III and IVa $(63 \%)$ than in strains of types IVb, V and VI $(17 \%)(\mathrm{p}<0.02)($ table IV). 
Table III. Relationship of haemagglutinating phenotypes of $E$. coli strains with virulence factors

\begin{tabular}{|c|c|c|c|c|c|c|c|c|}
\hline \multirow{2}{*}{$\begin{array}{c}\text { Haemagglutinating } \\
\text { phenotypes }\end{array}$} & \multicolumn{2}{|c|}{ Number $(\%)^{*}$ of strains from } & \multicolumn{6}{|c|}{ Number $(\%) \dagger$ of strains that were } \\
\hline & blood $(n=37)$ & faeces $(n=40)$ & $\mathrm{Hly}^{+}$ & $\mathrm{CNF}^{+}$ & lethal $^{+}$ & toxigenic $^{+} \ddagger$ & $\mathrm{PF}^{+} \S$ & hydrophobic \\
\hline MRHA $^{+}$MSHA $^{-}$ & $6(16)$ & $7(18)$ & $4(31)$ & $6(46)$ & $4(31)$ & $6(46)$ & $4(31)$ & $4(31)$ \\
\hline $\mathrm{MRHA}^{+} \mathrm{MSHA}^{+}$ & $16(43)$ & $5(13)$ & $9(43)$ & $11(52)$ & $8(38)$ & $12(57)$ & $8(38)$ & $9(43)$ \\
\hline MRHA $^{-}$MSHA $^{+}$ & $4(11)$ & $16(40)$ & $2(10)$ & $1(5)$ & $1(5)$ & $3(15)$ & $0(0)$ & $5(25)$ \\
\hline MRHA $^{-}$MSHA $^{-}$ & $11(30)$ & $12(30)$ & $0(0)$ & $0(0)$ & $3(13)$ & $3(13)$ & $0(0)$ & $0(0)$ \\
\hline
\end{tabular}

* Percentages were calculated in relation to the total number of bacteraemic and faecal strains respectively.

$\dagger$ Percentages were calculated in relation to the total number of strains showing each haemagglutinating phenotype.

$\ddagger$ Strains that were $\mathrm{Hly}^{+}, \mathrm{CNF}^{+}$or lethal ${ }^{+}$were considered toxigenic.

$\S$ P fimbriate.

Table IV. Virulence factors in E. coli strains belonging to different MRHA types

\begin{tabular}{|c|c|c|c|c|c|c|c|c|c|c|c|c|c|c|}
\hline \multirow[b]{2}{*}{$\begin{array}{c}\text { MRHA } \\
\text { type* }\end{array}$} & \multicolumn{6}{|c|}{$\begin{array}{l}\text { MRHA with erythrocytes } \\
\text { of } \dagger\end{array}$} & \multicolumn{2}{|c|}{$\begin{array}{l}\text { Number }(\%) \ddagger \text { of } \\
\text { strains from }\end{array}$} & \multicolumn{6}{|c|}{ Number $(\%) \ddagger$ of strains that were } \\
\hline & hA & $\mathrm{Cl}$ & $\mathrm{Gp}$ & $\mathrm{Ck}$ & $\mathrm{Sh}$ & $\mathrm{Pg}$ & $\begin{array}{c}\text { blood } \\
(\mathrm{n}=37)\end{array}$ & $\begin{array}{l}\text { faeces } \\
(n=40)\end{array}$ & Hly $^{+}$ & $\mathrm{CNF}^{+}$ & lethal $^{+}$ & toxigenic $^{+} \ddagger$ & $\mathrm{PF}^{+}$ & $\begin{array}{l}\text { hydro- } \\
\text { phobic }\end{array}$ \\
\hline III & $\mathbf{R} \S$ & V & V & V & $\mathbf{R}$ & $\mathbf{R}$ & $3(8)$ & $1(2)$ & $4(100)$ & $4(100)$ & $4(100)$ & $4(100)$ & $0(0)$ & $4(100)$ \\
\hline IVa & $\mathrm{R}$ & V & V & V & $\mathbf{R}$ & $\mathbf{R}$ & $10(27)$ & $2(5)$ & $8(67)$ & $11(92)$ & $7(58)$ & $12(100)$ & $12(100)$ & $6(50)$ \\
\hline IVb & $\mathbf{R}$ & V & V & V & - & $\mathbf{R}$ & $6(16)$ & $0(0)$ & $0(0)$ & $0(0)$ & $0(0)$ & $0(0)$ & $0(0)$ & $1(17)$ \\
\hline V & $\mathbf{R}$ & - & - & - & - & - & $1(3)$ & $5(13)$ & $0(0)$ & $0(0)$ & $0(0)$ & $0(0)$ & $0(0)$ & $1(17)$ \\
\hline VI & - & V & V & V & V & $\mathrm{V}$ & $2(5)$ & $4(10)$ & $1(17)$ & $2(33)$ & $1(17)$ & $2(33)$ & $0(0)$ & $1(17)$ \\
\hline
\end{tabular}

* Type I (RR-R--) and type II (-R-R--) are expressed by enterotoxigenic E. coli (ETEC) strains with CFA/I and CFA/II respectively.

$\dagger \mathrm{hA}=$ Human group $\mathrm{A} ; \mathrm{Cl}=$ calf; $\mathrm{Gp}=$ guinea pig; $\mathrm{Ck}=$ chicken; $\mathrm{Sh}=$ sheep; $\mathrm{Pg}=$ pig. $\mathrm{R}=\mathrm{MRHA} ;-=$ no $\mathrm{MRHA} ; \mathrm{V}=$ some strains MRHA and others no MRHA.

$\ddagger$ See footnote to table III.

$\S$ Strains belonging to MRHA type III showed MRHA with human erythrocytes only after incubation at $4^{\circ} \mathrm{C}$, whereas strains belonging to MRHA type IVa were MRHA with human erythrocytes at room temperature.

\section{P fimbriae}

The expression of $P$ fimbriae was investigated in all $77 \mathrm{E}$. coli strains grown on CFA agar. Seven of the 77 strains were tested after being grown on both CFA and Minca-Is media because three of them were MRHA only when grown on Minca-Is and the other four developed different MRHA types on Minca-Is than on CFA agar. Twelve P-fimbriate strains were detected: 10 from blood $(27 \%)$ and 2 $(5 \%)$ from faeces $(\mathrm{p}<0.02)$. All 12 P-fimbriate strains developed MRHA on both growth media used; 10 of them expressed the MRHA type IVa when grown on CFA and Minca-Is media, one strain expressed the MRHA type IVa when grown on CFA and the MRHA type $V$ when grown on Minca-Is, and the remaining strain expressed the MRHA type $V$ when grown on CFA and the
MRHA type IVa when grown on Minca-Is. The correlation between expression of the $P$ fimbriae and the MRHA type IVa was complete, because all P-fimbriate strains expressed the MRHA type IVa and all the strains belonging to the MRHA type IVa were $P$ fimbriate (table IV).

\section{Production of toxins}

In assays for CNF, eleven strains gave positive results in both Vero cell and rabbit skin assays whereas five strains only produced necrosis in rabbit skin and two only caused the typical morphological transformation of Vero cells. Eighteen CNF strains were detected-14 (38\%) from blood and $4(10 \%)$ from faeces $(\mathrm{p}<0.01)$ (table I).

Fifteen strains produced haemolysin (Hly), and 
14 of them also synthesised CNF. Furthermore, 16 strains were lethal for mice. According to these three toxic markers (CNF, Hly and lethality), $E$. coli strains were grouped into six different toxic phenotypes (table V). The most frequent toxic phenotype, $\mathrm{Hly}^{+} \mathrm{CNF}^{+}$lethal ${ }^{+}$, was exhibited by $9(24 \%)$ of the bacteraemic strains and by $1(3 \%)$ faecal strain $(p<0.02)$. This toxic phenotype was shown by all four strains belonging to MRHA type III and by six of the 12 P-fimbriate strains expressing MRHA type IVa. CNF production is clearly closely associated with haemolysin production and lethality for mice, because $14(78 \%)$ of the $18 \mathrm{CNF}$ strains were $\mathrm{Hly}^{+}$and $11(61 \%)$ were lethal for mice. Another common toxic phenotype was $\mathrm{Hly}^{-} \mathrm{CNF}^{-}$lethal $^{+}$which was shown by five strains, all of them isolated from the faeces of healthy people. Only one of these five strains was MRHA $^{+}$, belonged to the MRHA type IVa and expressed $\mathbf{P}$ fimbriae. Striking differences in the production of Hly, CNF and lethality were observed when $E$. coli strains were grouped according to their haemagglutinating properties (table III). Thus, the production of Hly, CNF or lethality for mice was detected in $53 \%$ of the $\mathrm{MRHA}^{+}$strains, whereas only $14 \%$ of the non-MRHA strains were $\mathrm{Hly}^{+}$ $\mathrm{CNF}^{+}$or lethal ${ }^{+}(\mathrm{p}<0.001)$. The production of toxins was a frequent property in strains belonging to specific MRHA types (table IV). Thus, all strains belonging to MRHA types III and IVa were $\mathrm{Hly}^{+}$, $\mathrm{CNF}^{+}$or lethal ${ }^{+}$, whereas no strain included in MRHA types IVb and V were toxigenic, and only $33 \%$ of strains of the MRHA type VI were toxigenic. Another interesting result was that all $12 \mathrm{P}$ fimbriate strains were toxigenic, 11 of them synthesising CNF. No LT-producing strain was detected and only one bacteraemic strain was found to synthesise VT. The VT-producing strain was also $\mathrm{Hly}^{+} \mathrm{CNF}^{+}$lethal $^{+}$, expressed the MRHA type III and belonged to serogroup $\mathrm{O} 4$.

\section{$O$ serogroups of $E$. coli}

Thirty-one strains were typable with the eight $O$ antisera used, $21(57 \%)$ isolated from blood and 10 $(25 \%)$ from faeces $(\mathrm{p}<0.01)$. Furthermore, virulence factors were more frequently detected in typable strains than in non-typable strains. Thus, $92 \%$ of P-fimbriate strains, $87 \%$ of $\mathrm{Hly}^{+}$and $78 \%$ of $\mathrm{CNF}^{+}$strains were typable (table VI). All E. coli strains belonging to serogroups $\mathrm{O} 4$ (five strains) and 06 (five strains) were isolated from blood, and the majority were toxigenic (nine strains) and expressed P fimbriae (seven strains) or MRHA type III (two strains). In contrast, all five strains belonging to the $\mathrm{Ol}$ group were isolated from the faeces, only one of them was toxigenic and expressed the $\mathbf{P}$ fimbriae.

\section{Discussion}

We have investigated the association of virulence factors with bacteraemic $E$. coli strains, using strains isolated from the faeces of healthy people as controls. In most bacteraemic strains, several virulence factors were found. Thus, our results support the idea that pathogenicity of bacteraemic $E$. coli may be ascribed to a combination of virulence factors.

CNF was shown to be a thermolabile cellassociated protein that causes necrosis in rabbit skin and induces specific morphological transformation of tissue cultures (Caprioli et al., 1983). Caprioli et al. (1987) and Bisicchia et al. (1985) found CNF production in $37 \%$ of $E$. coli strains from urinary tract infections, in $5 \%$ from diarrhoeic patients and in only $0.9 \%$ of strains isolated from the faeces of healthy people. In previous studies, we also detected a high prevalence of CNFproducing $E$. coli in urinary tract infections $(50 \%)$ (Alonso et al., 1987) and in $\mathrm{MRHA}^{+}$strains isolated from diarrhoeic patients $(49 \%)$ (Blanco et al.,

Table V. Relationship of toxic phenotypes of $E$. coli strains with mannose-resistant haemagglutination and $O$ groups

\begin{tabular}{|c|c|c|c|c|c|c|c|c|}
\hline & & & \multicolumn{2}{|c|}{ Number of strains from } & \multicolumn{3}{|c|}{ MRHA type (O groups) } & \multirow{2}{*}{$\frac{\text { Not-MRHA }}{\text { (O groups) }}$} \\
\hline \multicolumn{3}{|c|}{ Toxic phenotype } & blood & faeces & III & IVa (P fimbriate) & VI & \\
\hline \multirow{2}{*}{$\begin{array}{l}\mathrm{Hly}^{+} \\
\text {Hly }^{+}\end{array}$} & $\mathrm{CNF}^{+}$ & Lethal $^{+}$ & 9 & 1 & $4(\mathrm{O} 4, \mathrm{O} 6, \mathrm{O} 75, \mathrm{NT})^{*}$ & $6(204,306,018)$ & 0 & 0 \\
\hline & $\mathrm{CNF}^{+}$ & & 3 & 1 & 0 & $2(04,06)$ & $1(08)$ & $1(\mathrm{NT})$ \\
\hline & $\mathrm{CNF}^{+}$ & Lethal ${ }^{+}$ & 0 & 1 & 0 & 0 & 1 (NT) & 0 \\
\hline \multirow{3}{*}{$\mathrm{Hly}^{+}$} & & & 0 & 1 & 0 & 0 & 0 & $1(08)$ \\
\hline & $\mathrm{CNF}^{+}$ & & 2 & 1 & 0 & $3(\mathrm{O} 2, \mathrm{O} 7, \mathrm{NT})$ & 0 & 0 \\
\hline & & Lethal $^{+}$ & 0 & 5 & 0 & $1(\mathrm{O} 1)$ & 0 & $4(\mathrm{NT})$ \\
\hline
\end{tabular}

\footnotetext{
* NT= not typable.
} 
Table VI. Relationship of $E$. coli serogroups with virulence factors

\begin{tabular}{|c|c|c|c|c|c|c|c|c|c|c|}
\hline \multirow[b]{3}{*}{ Serogroup } & \multicolumn{10}{|c|}{ Number $(\%)^{*}$ of strains that were } \\
\hline & \multicolumn{2}{|c|}{ isolated from } & \multirow[b]{2}{*}{$\mathrm{Hly}^{+}$} & \multirow[b]{2}{*}{$\mathrm{CNF}^{+}$} & \multirow[b]{2}{*}{ lethal $^{+}$} & \multirow[b]{2}{*}{ toxigenic $^{+}$} & \multicolumn{3}{|c|}{ MRHA type } & \multirow{2}{*}{$\begin{array}{l}\text { hydro- } \\
\text { phobic }\end{array}$} \\
\hline & blood & faeces & & & & & III & $\mathrm{IVa}\left(\mathrm{FP}^{+}+\right)$ & others & \\
\hline $\mathrm{Ol}$ & 0 & 5 & 0 & 0 & 1 & 1 & 0 & 1 & 1 & 0 \\
\hline $\mathrm{O} 2$ & 4 & 2 & 0 & 1 & 0 & 1 & 0 & 1 & 1 & 1 \\
\hline $\mathrm{O} 4$ & 5 & 0 & 4 & 4 & 3 & 4 & 1 & 3 & 0 & 3 \\
\hline 06 & 5 & 0 & 5 & 5 & 4 & 5 & 1 & 4 & 0 & 4 \\
\hline 07 & 1 & 0 & 0 & 1 & 0 & 1 & 0 & 1 & 0 & 0 \\
\hline 08 & 4 & 2 & 2 & 1 & 0 & 2 & 0 & 0 & 2 & 1 \\
\hline 018 & 1 & 1 & 1 & 1 & 1 & 1 & 0 & 1 & 1 & 0 \\
\hline O75 & 1 & 0 & 1 & 1 & 1 & 1 & 1 & 0 & 0 & 1 \\
\hline Total typable strains & 21 & 10 & $13(42)$ & $14(67)$ & $10(32)$ & $16(52)$ & $3(10)$ & $11(35)$ & $5(16)$ & $10(32)$ \\
\hline Not typable strains & 16 & 30 & $2(4)$ & $4(9)$ & $6(13)$ & $8(22)$ & $1(2)$ & $1(2)$ & $13(28)$ & $8(17)$ \\
\hline$\chi^{2} \mathrm{p}$ value & $\mathrm{p}<$ & 0.01 & $\mathrm{p}<0.001$ & $\mathrm{p}<0.001$ & $\mathrm{p}<0.1$ & $\mathrm{p}<0.01$ & $\mathrm{p}<0.5$ & $\mathrm{p}<0.001$ & $\mathrm{p}<0.5$ & $\mathrm{p}<0.3$ \\
\hline
\end{tabular}

* Percentages were calculated in relation to the total number of typable and non typable strains.

$\dagger$ All strains with MRHA type IVa expressed P fimbriae.

$1988 a$ ). In this study, we found CNF production in $38 \%$ of bacteraemic strains and $10 \%$ of control strains isolated from normal stools $(\mathrm{p}<0.01)$. The production of CNF has been reported to be closely associated with the production of Hly, the expression of mannose-resistant haemagglutination, and lethality (Bisicchia et al., 1985; Alonso et al., 1987; Caprioli et al., 1987; Blanco et al., 1988a). Our results corroborate these associations, since among the 18 CNF-producing strains, $14(78 \%)$ were $\mathrm{Hly}^{+}, 17(94 \%)$ expressed MRHA and $11(61 \%)$ were lethal for mice. Furthermore, another virulence factor, the production of $\mathbf{P}$ fimbriae, was found to be associated with CNF-producing strains. Thus, $11(61 \%)$ of the $18 \mathrm{CNF}^{+}$strains expressed $\mathbf{P}$ fimbriae, whereas only one $(2 \%)$ of the $59 \mathrm{CNF}^{-}$ strains were $P$ fimbriate $(p<0.001)$. In our study, $90 \%$ of the P-fimbriate bacteraemic strains were isolated from patients with confirmed urinary tract infections or with clinical evidence that a urinary infection was the probable source of the bacteraemia. $\mathbf{P}$ fimbriae were previously detected in the majority (90-100\%) of $E$. coli strains isolated from pyelonephritis (Väisänen et al., 1981; Domingue et al., 1985).

A less than absolute correlation between the detection of CNF on Vero cells and in rabbit skin tests was observed. This may be due to a lack of sensitivity of the assays employed. However, it is also possible that more than one type of necrotising toxin may exist in bacteraemic $E$. coli. Two types of necrotising toxins, differentiated by means of seroneutralisation assays, have been previously detected in $E$. coli strains isolated from calves with diarrhoea. However, both necrotising toxins showed a similar transformation of Vero cells to that produced by CNF (De Rycke et al., 1987; Blanco et al., 1988b).

Previous studies have concluded that the majority of bacteraemic $E$. coli strains belong to a limited number of serogroups-O1, O2, O4, O6, 07, O8, O18 and 075 (Vosti et al., 1964; Ørskov and Ørskov, 1975; Cross et al., 1984; Brauner et al., 1985). These $O$ groups were also frequently detected in $E$. coli strains isolated from diverse extraintestinal infections, but they were rarely found in strains isolated from the stools of healthy people (Ørskov and Ørskov, 1985). The suggestion has been repeatedly made that $E$. coli strains belonging to those serogroups possess specific virulence factors which confer on them their special invasive ability. Our results support this suggestion. Thus, $92 \%$ of P-fimbriate strains, $87 \%$ of $\mathrm{Hly}^{+}, 78 \%$ of $\mathrm{CNF}^{+}$ and $63 \%$ of lethal strains belonged to these serogroups. Virulence factors occurred especially in strains of serogroups $\mathrm{O} 4$ and $\mathrm{O6}$, a result which is in agreement with those obtained by other authors (Czirók, 1985; O'Hanley et al., 1985; Blanco et al., 1988a).

As in previous studies (Ljungh and Wadström, 1982; González et al., 1988), we have found that haemagglutinating strains are usually hydrophobic. However, the bacteraemic strains aggregating mostly at ammonium sulphate concentrations of 
1.0-1.4 M, are less hydrophobic than enterotoxigenic strains with colonisation factor CFA/I (ISAT $0.04 \mathrm{M}$ ) or CFA/II (ISAT 0.1-0.4 M).

Minshew et al. (1978) showed an association of Col V production with $E$. coli isolates from blood. However, Quackenbush and Falkow (1979) found that the common occurrence of the $\mathrm{Col} \mathrm{V}$ plasmid in invasive $E$. coli did not imply that $\mathrm{Col} \mathrm{V}$ had any influence on the virulence of such strains. Our results indicate that production of $\mathrm{Col} \mathrm{V}$ is neither more frequent in bacteraemic than in control strains, nor is it associated with lethality.

We have previously developed a simple, rapid and economical typing system of $E$. coli strains based on their mannose-resistant haemagglutination pattern that was found to be useful for the presumptive identification of pathogenic strains (Blanco et al., 1985, 1988a). Results of this study confirm the utility of our MRHA typing system. Taking into account the results obtained in this study and those previously reported (Blanco et al., 1985, 1988a), we now know that MRHA types I and II are expressed only by enterotoxigenic $E$. coli (producing LT or STa, or both, enterotoxins) with

\section{REFERENCES}

Alonso M, Blanco J, Blanco M, González E A 1987 Frequent production of toxins by Escherichia coli strains isolated from human urinary tract infections : relation with haemagglutination. FEMS Microbiology Letters 48: 391-396.

Bisicchia R, Ciammarughi R, Caprioli A, Falbo V, Ruggeri F $M 1985$ Toxin production and haemagglutination in strains of Escherichia coli from diarrhoea in Brescia, Italy. Journal of Hygiene 95 : 353-361.

Blanco J, González E A, Anadón R 1985 Colonization antigens and haemagglutination patterns of human Escherichia coli. European Journal of Clinical Microbiology 4: 316-326.

Blanco J, González E A, Blanco M, Alonso M P, Barbadillo M $\mathrm{J} 1988 a$ Toxins and serotypes of faecal non-enterotoxigenic and non-enteropathogenic Escherichia coli strains causing mannose-resistant haemagglutination : relation with haemagglutination patterns. Zentralblatt für Bakteriologie Mikrobiologie und Hygiene Originale A 269 : 43-55.

Blanco J, González E A, Garcia S, Blanco M, Regueiro B, Bernárdez I $1988 b$ Production of toxins by Escherichia coli strains isolated from calves with diarrhoea in Galicia (North-western Spain). Veterinary Microbiology 18: 297311.

Brauner A, Leissner M, Wretlind B, Julander I, Svenson S B, Källenius G 1985 Occurrence of P-fimbriated Escherichia coli in patients with bacteremia. European Journal of Clinical Microbiology 4: 566-569.

Brauner A et al. 1987 The use of biochemical markers, serotype and fimbriation in the detection of Escherichia coli clones. Journal of General Microbiology 133: 2825-2834.

Caprioli A, Falbo V, Roda L G, Ruggeri F M, Zona C 1983 Partial purification and characterization of an Escherichia coli toxic factor that induces morphological cell alterations. Infection and Immunity 39: 1300-1306. colonisation factors CFA/I and CFA/II respectively; MRHA type III appears in CNF-producing strains without $P$ fimbriae; MRHA type IVa is specific for CNF producing P-fimbriate strains; and MRHA types IVb, V and VI are usually expressed by $E$. coli without virulence factors. Interestingly, in this study MRHA type IVb was only found in bacteraemic $E$. coli strains $(\mathrm{p}<0.05)$. This merits further study.

In conclusion, we have found that bacteraemic E. coli strains show virulence factors similar to those shown by strains responsible for urinary tract infections, such as the production of CNF and Hly and the expression of $\mathbf{P}$ fimbriae. We have also confirmed that our modified MRHA typing system is a simple and reliable method for presumptive identification of pathogenic $E$. coli.

This study was supported by a grant from the Xunta de Galicia (Autonomous Government of Galicia, Spain) (XUGA84301188). M. B. and J. I. G. acknowledge the Ministerio de Educación y Ciencia (Spain) for the F.P.I. research fellowships. We thank S. Fernández for skilful technical assistance.

Caprioli A et al. 1987 Cytotoxic necrotizing factor production by hemolytic strains of Escherichia coli causing extraintestinal infections. Journal of Clinical Microbiology 25: 146149.

Cross A S, Gemski P, Sadoff J C, Ørskov F, Ørskov I 1984 The importance of the $\mathrm{K} 1$ capsule in invasive infections caused by Escherichia coli. Journal of Infectious Diseases 149: 184193.

Czirók E 1985 Virulence factors of Escherichia coli. II. Antigens O4, $\mathrm{O} 6$ and 018 , haemolysin production and mannose resistant haemagglutinating capacity are closely associated. Acta Microbiologica Hungarica 32: 183-192.

De Rycke J, Guillot J F, Boivin R 1987 Cytotoxins in nonenterotoxigenic strains of Escherichia coli isolated from feces of diarrheic calves. Veterinary Microbiology 15: 137150.

Domingue G J et al. 1985 Pathogenic significance of Pfimbriated Escherichia coli in urinary tract infections. Journal of Urology 133: 983-989.

Duguid J P, Clegg S, Wilson M I 1979 The fimbrial and nonfimbrial haemagglutinins of Escherichia coli. Journal of Medical Microbiology 12: 213-227.

Evans D J, Evans D G, Young LS, Pitt J 1980 Hemagglutination typing of Escherichia coli: definition of seven hemagglutination types. Journal of Clinical Microbiology 12: 235-242.

Evans D J et al. 1981 Hemolysin and $\mathrm{K}$ antigens in relation to serotype and hemagglutination type of Escherichia coli isolated from extraintestinal infections. Journal of Clinical Microbiology 13: 171-178.

Gaastra W, de Graaf F K 1982 Host-specific fimbrial adhesins of noninvasive enterotoxigenic Escherichia coli strains. Microbiological Reviews 46: 129-161.

González E A, Blanco J 1985 Production of cytotoxin VT in enteropathogenic and non-enteropathogenic Escherichia 
coli strains of porcine origin. FEMS Microbiology Letters 26: $127-130$.

González E A, Blanco J, Baloda S B, Wadström T 1988 Relative cell surface hydrophobicity of Escherichia coli strains with various recognized fimbrial antigens and without recognized fimbriae. Zentralblatt für Bakteriologie Mikrobiologie und Hygiene Originale A 269: 218-236.

Guinée P A M, Agterberg C M, Jansen W H 1972 Escherichia coli $\mathrm{O}$ antigen typing by means of a mechanized microtechnique. Applied Microbiology 24: 127-131.

Guinée P A M, Veldkamp J, Jansen W H 1977 Improved minca medium for the detection of $\mathrm{K} 99$ antigen in calf enterotoxigenic strains of Escherichia coli. Infection and Immunity 15: 676-678.

Hacker J, Schrettenbrunner A, Schröter G, Düvel H, Schmidt G, Goebel W 1986 Characterization of Escherichia coli wildtype strains by means of agglutination with antisera raised against cloned P-, S-, and MS-fimbriae antigens, hemagglutination, serotyping and hemolysin production. Zentralblatt für Bakteriologie Mikrobiologie und Hygiene Originale A 261 : 219-231.

Johnson J R, Moseley S L, Roberts P L, Stamm W E 1988 Aerobactin and other virulence factor genes among strains of Escherichia coli causing urosepsis: association with patient characteristics. Infection and Immunity 56: 405-412.

Korhonen T K et al. 1985 Serotypes, hemolysin production, and receptor recognition of Escherichia coli strains associated with neonatal sepsis and meningitis. Infection and Immunity 48: 486-491.

Kreger B E, Craven D E, Carling P C, McCabe W R 1980 Gram-negative bacteremia. III. Reassessment of etiology, epidemiology and ecology in 612 patients. American Journal of Medicine 68: 332-343.

Levine M M 1987 Escherichia coli that cause diarrhea: enterotoxigenic, enteropathogenic, enteroinvasive, enterohemorrhagic, and enteroadherent. Journal of Infectious Diseases 155: 377-389.
Ljungh A, Wadström T 1982 Salt aggregation test for measuring cell surface hydrophobicity of urinary Escherichia coli. European Journal of Clinical Microbiology 1 : 388-392.

Minshew B H, Jorgensen J, Counts G W, Falkow S 1978 Association of hemolysin production, hemagglutination of human erythrocytes, and virulence for chicken embryos of extraintestinal Escherichia coli isolates. Infection and Immunity $20: 50-54$

Montgomerie J Z, Bindereif A, Neilands J B, Kalmanson G M, Guze L B 1984 Association of hydroxamate siderophore (aerobactin) with Escherichia coli isolated from patients with bacteremia. Infection and Immunity 46: 835-838.

O'Hanley $\mathrm{P}$ et al. $1985 \mathrm{Gal}-\mathrm{Gal}$ binding and hemolysin phenotypes and genotypes associated with uropathogenic Escherichia coli. New England Journal of Medicine 313: 414420.

Ørskov F, Ørskov I 1975 Escherichia coli O:H serotypes isolated from human blood. Prevalence of the $\mathrm{K} 1$ antigen with technical details of $\mathrm{O}$ and $\mathrm{H}$ antigen determination. Acta Pathologica et Microbiologica Scandinavica Section B (Suppl) 83: 585-600.

Ørskov I, Ørskov F 1985 Escherichia coli in extra-intestinal infections. Journal of Hygiene 95 : 551-575.

Quackenbush R L, Falkow S 1979 Relationship between colicin $\mathrm{V}$ activity and virulence in Escherichia coli. Infection and Immunity 24: 562-564.

Väisänen V et al. 1981 Mannose-resistant haemagglutination and $P$ antigen recognition are characteristic of Escherichia coli causing primary pyelonephritis. Lancet 2, 1366-1369.

Vosti K L, Goldberg L M, Monto A S, Rantz L A 1964 Host parasite interaction in patients with infections due to Escherichia coli. I. The serogrouping of $E$. coli from intestinal and extraintestinal sources. Journal of Clinical Investigation 43: 2377-2385.

Weinstein R, Young L S 1978 Phagocytic resistance of Escherichia coli $\mathrm{K}-1$ isolates and relationship to virulence. Journal of Clinical Microbiology 8: 748-755. 